\title{
Coal halos induced by uranium mineral radiation
}

\author{
MARTINA HAVELCOVÁ ${ }^{1}$, VLADIMÍR MACHOVIČ ${ }^{1}$, IVANA \\ SÝKOROVÁ ${ }^{1}$ \\ ${ }^{1}$ Institute of Rock Structure and Mechanics of the Czech \\ Academy of Sciences, V Holešovičkách 41, Prague 8, \\ 182 09, Czech Republic
}

Coal samples with uranium mineralization were studied for detailed assessment of the structure of radiation-induced halos in bituminous coal with numerous inclusions of uraninite and coffinite. The uranium content in inclusions in the samples studied ranged from 40 to $50 \mathrm{wt} \%$. The degree of radiolytic alteration increased steadily from the outer edge of the halo towards the radioactive inclusion, and the maximum structural and chemical changes in coal matrix were found at about $10-20 \mu \mathrm{m}$ from the edge of the inclusions.

Raman mapping microspectroscopy was used as an advantageous high spatial resolution method. Raman structural parameters such as full width at half maximum (FWHM-D), the positions of the D-band and G-band peaks and their area ratios were calculated, and these correlated well with vitrinite reflectance. Using linear profiles across the entire halos, changes in the degree of radiolytic alteration of coal matter caused by ionizing radiation resulting from the decay of uranium and its daughter products, were described. The diameter of the halos and progress of dependent alterations, such as variations in the FWHM-D with distance from inclusion, can be ascribed to the energy of passing ionizing particles, the shape and size of the three-dimensional inclusion, the reaction scheme, density of the original coal and the density of altered coal, whose density increases by alteration while the range of particles are shortened.

Using micro-ATR-FTIR, oxidative radiolytic alteration of coal was identified in halos, with oxidization to alcohols, ketones and carboxyl groups, which were then converted to $\mathrm{COO}^{-}$ions bound to the cations present, including $\mathrm{UO}_{2}{ }^{2+}$. Generally, radiolytic alteration increased the structural organization of coal, and it can be concluded that the conversion of the original coal to a type of anthracite occurred during the process of $\mathrm{C}-\mathrm{H}$ and $\mathrm{C}-\mathrm{C}$ cleavage, dehydroaromatization of naphthenic rings and oxidation resulting in the transformation of aliphatic structures into aromatic clusters. 